\title{
Surgical Referral for Carotid Artery Stenosis - The Influence of NASCET
}

\author{
T.J. Coyne and M.C. Wallace
}

\begin{abstract}
A retrospective review was undertaken of 139 consecutive patients with presumed carotid artery stenosis referred to a vascular neurosurgeon. The review period included three years prior and one year subsequent to the publication of the North American Symptomatic Carotid Endarterectomy Trial (NASCET) preliminary results showing surgery to be superior to best medical therapy for patients with symptomatic, high grade ( $>70 \%$ linear diameter) carotid stenosis. The aims of this analysis were to determine any changes in the referral pattern following the NASCET publication (post-NASCET), and to examine the use and reliability for surgical decision making of pre-referral carotid artery imaging. Patient referral rate increased markedly post-NASCET, particularly from neurologists. There was a trend for more post-NASCET referrals to be for high grade stenosis and fewer referrals to be for intermediate grade (30-69\% linear diameter) stenosis, although continued referral of patients with intermediate grade stenosis is desirable as randomization into NASCET continues for this group of patients. Ninety-six patients $(69 \%)$ were referred with carotid duplex ultrasonography having been performed. There was poor correlation of these results with angiography, which remains necessary for planning management. A majority of patients $(65 \%)$ referred to this surgical practice did not come to surgery.
\end{abstract}

\begin{abstract}
Résumé: Consultation chirurgicale pour sténose carotidienne - l'influence de NASCET. Nous avons revisé les cas de 139 patients consécutifs référés à un chirurgien vasculaire pour sténose carotidienne. Ces cas avaient été référés sur une période de trois ans avant et d'un an après la publication des résultats préliminaires de l'étude nord-américaine sur l'endartérectomie carotidienne chez les patients symptômatiques (North American Symptomatic Carotid Endarterectomy Trial - NASCET) montrant que la chirurgie était supérieure au meilleur traitement médical chez les patients symptômatiques, porteurs d'une sténose carotidienne sévère ( $>70 \%$ de diamètre linéaire). Les buts de cette analyse étaient de déterminer s'il y avait eu des changements dans les habitudes de référence suite à la publication de NASCET (post-NASCET) et d'examiner l'utilité et la fiabilité de l'imagerie carotidienne faite avant la consultation en chirurgie vasculaire pour la prise de décision chirurgicale. Le taux de référence a augmenté considérablement post-NASCET, surtout de la part des neurologues. Post-NASCET, les médecins avaient tendance à référer plus de patients avec une sténose sévère et moins de patients avec une sténose modérée (30-69\% de diamètre linéaire). Cependant, il est souhaitable que les patients avec une sténose modérée continuent à être référés parce que la randomisation dans l'étude NASCET se poursuit pour ce groupe de patients. L'ultrasonographie duplex carotidienne avait déjà été faite avant la consultation chez quatre-vingt-seize patients $(69 \%)$. La corrélation avec les résultats de l'angiographie, qui demeure nécessaire à l'établissement d'un plan de traitement, était faible. La majorité des patients $(65 \%)$ qui nous ont été référés n'ont pas été soumis à la chirurgie.
\end{abstract}

Can. J. Neurol. Sci. 1994; 21: 129-132

In April 1991, the North American Symptomatic Carotid Endarterectomy Trial (NASCET) issued a clinical alert, notifying physicians that randomization into the trial of patients with high grade $(70-99 \%$ linear diameter) stenosis had ceased due to the demonstrable benefit of endarterectomy in addition to best medical therapy in preventing future stroke in this group of patients.' This was followed in August 1991 by publication of these results. ${ }^{2}$ At about the same time, the European Carotid Surgery Trial (ECST) also reported on the efficacy of surgery in a similar group of patients. ${ }^{3}$ In North America, the NASCET results were widely reported in journals intended for primary care physicians, internists, neurologists, neurosurgeons and vascular surgeons. ${ }^{4-10}$
We felt it would be of interest to review the referral to a vascular neurosurgeon of patients with suspected carotid artery stenosis, to determine any changes in referral pattem subsequent to the NASCET publication. An additional aim was to examine carotid artery imaging performed prior to referral, and to compare the usefulness of ultrasound with that of carotid angiography in this group of patients.

From the Division of Neurosurgery, The Toronto Hospital and University of Toronto, Toronto.

RECEIVED AUGUST 3, 1993. ACCEPTED IN FINAL. FORM NOVEMBER 25, 1993.

Reprint requests to: Dr. T.J. Coyne, Division of Neurosurgery. The Toronto Hospital, 399 Bathurst Sreet, Toronto, Ontario, Canada M5T 2S8 


\section{MethodS AND Materials}

The records of 139 consecutive patients referred with a diagnosis of suspected carotid artery stenosis were retrospectively reviewed. The referrals were to the practice of the senior author (MCW), a vascular neurosurgeon practising in a large metropolitan teaching centre, and a NASCET participant. The review covered the four year period from August 1988 to August 1992, thus covering the three years prior to publication of the preliminary NASCET results (pre-NASCET), and the first year following this publication (post-NASCET).

The number of referrals/year, source of referral, indication for referral, nature of pre-referral carotid artery imaging, and correlation of duplex ultrasound with angiography were specifically examined. Final diagnosis and management decision were also analyzed.

Statistical analyses were performed using the chi-square test.

\section{RESULTS}

The male:female ratio for the 139 patients was $1.5: 1$, and the mean age was 64 years (range 19-87 years). Pre-NASCET, patients were referred at an average rate of 28 patients/year. During the year post-NASCET, 55 patients were referred. The sex ratio and mean age were identical pre- and post-NASCET.

Pre-NASCET, neurologists were the referral source for $42 / 84$ patients (50\%), with family physicians referring 24 (29\%), other neurosurgeons $12(14 \%)$, and others (e.g., internists, ophthalmologists) 6 patients (7\%). Post-NASCET, neurologists were the referral source for $39 / 55$ patients $(71 \%)$, a three-fold increase in the rate of referral by neurologists $(p<0.05)$ (Table 1). Thirteen (24\%) patients post-NASCET were referred by family physicians, and $3(5 \%)$ by other physicians.

Table 1. Referral Patterns Prior to (Pre-NASCET) and Subsequent to (Post-NASCET) Publication of NASCET Preliminary Results ${ }^{2}$

\begin{tabular}{lcc}
\hline & Pre-NASCET & Post-NASCET \\
\hline $\begin{array}{l}\text { Referral rate } \\
\quad \text { Patients/year) }\end{array}$ & 28 & 55 \\
Patients referred by neurologists & $42 / 84$ & $39 / 55$ \\
& $(50 \%)$ & $(71 \%)$ \\
Patients referred at :- & $30 / 84$ & $16 / 55$ \\
$*<$ one month & $(36 \%)$ & $(29 \%)$ \\
& $21 / 84$ & $16 / 55$ \\
$*$ one - three months & $(25 \%)$ & $(29 \%)$ \\
& $33 / 84$ & $23 / 55$ \\
$*>$ three months & $(39 \%)$ & $(42 \%)$ \\
\hline from time of initial symptom(s) & & \\
\hline
\end{tabular}

The most common symptom leading to referral was hemispheric transient ischaemic attack (TIA), occurring in 59/139 patients $(42 \%)$. Stroke was the reason for referral in 38 patients $(27 \%)$, and amaurosis fugax in $25(18 \%)$. Six patients $(4 \%)$ were referred with asymptomatic bruits, and a miscellaneous group of symptoms (one or more of dizziness, vertigo, syncope, seizure, episodic confusion, diplopia, or headache) led to referral in the remaining 11 patients $(9 \%)$. There was no difference in indication for referral pre- and post-NASCET.
Fifty of the 139 patients (36\%) were referred within one month of the onset of symptoms, 35 (25\%) from one to three months, and $54(39 \%)$ at greater than three months following symptom onset. There was no difference pre- and postNASCET in the time from symptom onset to referral (Table 1).

The majority of patients $(121 / 139,87 \%)$ were referred with a carotid artery imaging study. Carotid duplex ultrasonography had been performed in 96 patients (69\%), and angiography in 33 (24\%). These percentages were not different post-NASCET compared to pre-NASCET. Two-thirds of patients with prereferral angiograms were referred by neurologists.

It was felt that 25 of the 139 referred patients (18\%) did not in fact have carotid artery stenosis, either by clinical or prereferral carotid artery imaging criteria. The proportion of patients thought not to have carotid artery stenosis did not differ pre- or post-NASCET. Most commonly, posterior circulation ischaemia was thought to be the basis of these patients' symptoms. Other diagnoses were migraine, hypoglycaemia, cardiac embolus, carotid artery dissection, and superior sagittal sinus thrombosis. In a number of patients no definitive diagnosis could be made. Of the remaining 114 patients, it was felt 11 had asymptomatic carotid stenosis. Six patients had incidentally noted bruits. The other five had symptoms thought by the referring physician to be ischaemic, along with a bruit and/or an imaging study demonstrating stenosis, but with the symptoms on review not felt to be related to the stenosis. These patients were not further investigated with angiography.

Of the 103 patients with probable symptomatic carotid stenosis, 15 did not have angiography performed, for reasons of either patient refusal, major neurological disability, carotid artery occlusion suggested on more than one ultrasonographic carotid artery examination, or having other serious medical problems that would preclude surgery regardless of angiographic findings.

The other 88 patients underwent angiography, either pre- or post-referral. Carotid artery stenosis expressed as a percentage was determined employing the NASCET methodology of measuring linear diameter stenosis. ${ }^{2}$ Table 2 demonstrates the management of these 88 patients. Of the original group of 139 patients referred because of presumed carotid artery disease, 48 (35\%) came to surgery.

Table 2. Management of 88 Patients Following Angiography

\begin{tabular}{|c|c|c|}
\hline Degree of Stenosis & \multicolumn{2}{|c|}{ Management (number of patients) } \\
\hline $70-99 \%$ & Endarterectomy (48) & \\
\hline (52 patients) & Medical therapy (4) & $\begin{array}{l}-2 \text { unfit for surgery } \\
-2 \text { declined surgery }\end{array}$ \\
\hline $30-69 \%$ & Endarterectomy (2) & - NASCET study \\
\hline (8 patients) & Medical therapy (6) & $\begin{array}{l}-1 \text { NASCET study } \\
-5 \text { ineligible for } \\
\text { NASCET }\end{array}$ \\
\hline $\begin{array}{l}0-30 \% \\
\text { (14 patients) }\end{array}$ & Medical Therapy (14) & \\
\hline $\begin{array}{l}\text { Occluded artery } \\
\text { (14 patients) }\end{array}$ & Medical Therapy (14) & \\
\hline
\end{tabular}


The degree of carotid artery stenosis as reported by pre-referral investigation was examined, placing the reported stenosis of the presumed symptomatic vessel into one of four categories - 0 $29 \%$ stenosis, $30-69 \%$ stenosis, $70-99 \%$ stenosis, and occlusion. Pre-NASCET, these four categories were equally represented. Post-NASCET, there was a trend to more patients being referred with investigations reporting $70-99 \%$ stenosis, and fewer with $30-69 \%$ stenosis or vessel occlusion. However this was not significant at the $\mathrm{p}<0.05$ level (Table 3 ).

Table 3. Degree of Carotid Artery Stenosis as Reported by Pre-Referral Imaging. Pre- and post-NASCET refer to before and after publication of NASCET preliminary results. ${ }^{2}$

\begin{tabular}{lcc}
\hline Degree of artery stenosis (\%) & Pre-NASCET & Post-NASCET \\
\hline & $\begin{array}{c}\text { Number of } \\
\text { patients } \\
(\mathbf{n = 5 4 )}\end{array}$ & $\begin{array}{c}\text { Number of } \\
\text { patients } \\
(\mathbf{n}=\mathbf{5 2})\end{array}$ \\
\hline $0-29$ & $7(13 \%)$ & $4(8 \%)$ \\
$30-69$ & $15(27 \%)$ & $10(19 \%)$ \\
$70-99$ & $23(43 \%)$ & $33(63 \%)$ \\
occluded & $9(17 \%)$ & $5(10 \%)$ \\
\hline
\end{tabular}

Combining pre- and post-referral imaging, 71 patients in this series had one or both carotid arteries imaged by both duplex ultrasound and angiography, for a total of 121 arteries examined by both modalities. The average time between the two investigations was 5.1 weeks (range one day to six months). Using the previously described categories of stenosis, the ultrasound and angiographic categories coincided in $79(65 \%)$ of arteries. In 24 instances $(20 \%)$, ultrasound reported a lower category of stenosis and in $18(15 \%)$ a higher category than that demonstrated by angiography. Ultrasound estimation disagreed with angiography at all degrees of stenosis. Ten vessels were reported as being occluded by ultrasound, of which two were shown to have 70$99 \%$ stenosis by angiography, and five arteries reported to have high grade stenosis on ultrasound were occluded when imaged with angiography. Of 29 vessels with $0-29 \%$ ultrasound stenosis, five had 30-69\% stenosis on angiography (although none had angiographic stenosis of $70-99 \%$ ).

\section{Discussion}

While it makes intuitive sense that carotid endarterectomy could decrease the incidence of stroke in patients with carotid artery stenosis, the value of the procedure came to be questioned during the $1980^{\prime}$ 's. 11,12 The NASCET conclusion that endarterectomy added to best medical therapy was beneficial in symptomatic patients with high grade stenosis was an important advancement in stroke prevention, and one that was widely publicized. ${ }^{24-10}$ Our review of the referral of patients with suspected carotid artery disease to the practice of an active cerebrovascular neurosurgeon demonstrates a number of changes in referral pattern since the original NASCET publication in August 1991.

The most striking change was a doubling of the rate of referral of patients, primarily due to a threefold increase in referral from neurologists. This suggests that prior to the NASCET results neurologists may have indeed been apprehensive about the value of endarterectomy, but have accepted the NASCET data and are now referring more patients for a surgical opinion. In addition, there was also an increase, although of less magnitude, in referrals from family physicians, implying that this group of physicians is also aware of the NASCET findings. It was noted that there were fewer referrals from other neurosurgeons in the time since the NASCET publication. This could be attributed to non-NASCET neurosurgeons, who had previously referred patients to the NASCET study, now managing patients independently.

It may have been expected that following the NASCET publication patients would have been referred earlier following the onset of symptoms, as the study demonstrated that the benefit of surgery for symptomatic patients with high grade stenosis was evident as early as one month following endarterectomy. ${ }^{2}$ However this did not happen in this series.

Although not reaching statistical significance, when prereferral carotid artery imaging was performed, there was a trend to a greater proportion of referred patients having high grade (70-99\%) stenosis post-NASCET than pre-NASCET. This raises two areas of concern. Firstly, there may be a perception amongst referring physicians that, as the symptomatic $70-99 \%$ stenosis group has been shown to benefit from surgery, this is the most important group to refer. However, the role of surgery for moderate $(30-69 \%)$ stenosis is not yet known, ${ }^{6.13}$ and it is important for patients with this degree of stenosis to continue to be referred where possible to a participating NASCET centre, so that this question may ultimately be answered. Secondly, if the NASCET results, which are defined in terms of angiographic stenosis, are being used to help decide whether or not to refer patients with carotid artery stenosis, it is important to be aware that duplex ultrasound, the investigation most commonly used in these patients, did not always agree with angiography. Ultrasound and angiography placed a vessel in the same category of stenosis in only two-thirds of cases. Angiographic stenosis was both over- and under-estimated by ultrasound, including the clinically important discrepancies of angiographic occlusion reported as stenosis, and angiographic high grade stenosis reported as occlusion. A number of studies have reported duplex ultrasound to have a high degree of correlation ( $>87 \%$ agreement) when compared with angiography. ${ }^{14-16}$ These reports have

\section{Final management for arteries grouped according to degree of ultrasound stenosis}

$\mathrm{U} / \mathrm{S}$ stenosis $30-69 \%$

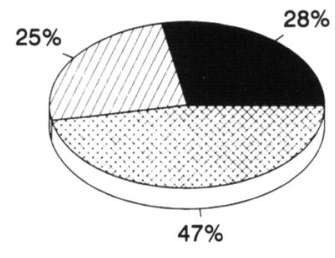

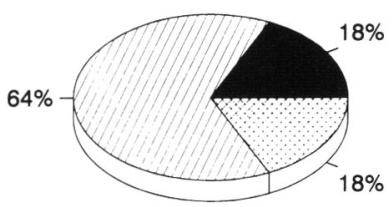

U/S stenosis $70-99 \%$
Best Medical Treatment $\square$ Carotid Endarterectomy $\square$ NASCET Candidate

Figure 1: Management for carotid arteries reported by ultrasound to have stenosis in the categories 30-69\% $(n=32)$ and $70.99 \%(n=50)$. Final management based on degree of stenosis demonstrated by angiography $(0-30 \%$ stenosis or occlusion - medical therapy: $30-69 \%$ stenosis - candidate for continuing arm of NASCET; $70.99 \%$ stenosis endarterectomy). If these guidelines were applied to the ultrasound findings, all on the chart on the left would have been NASCET candidates, and all on the chart on the right directed to endarterectomy. 
generally originated from large institutions with dedicated vascular laboratories. The ultrasound reports that accompanied patients with referral in this series came from a broad cross-section of community radiological practices, local hospitals and tertiary referral centres, and the correlation with angiography was not high enough to allow these reports to be used in clinical decision making. If all 121 vessels imaged with both modalities had been symptomatic, the management strategies based on angiography would have been diverse within a given category of ultrasound stenosis (Figure 1). It is interesting to note that one-quarter of patients referred from neurologists had an angiogram performed prior to referral, suggesting that many neurologists also feel that an angiogram is necessary to aid in management decision-making.

A further point of interest concerns the choice of management for this group of patients. Patients are likely referred to a surgeon because the referring physician feels surgery is a treatment option to be considered, and these patients are therefore already a selected group of all patients with the presumed disease. However, of the patients consecutively referred in this series, it was felt one-fifth did not in fact have symptomatic carotid artery stenosis, and only one-third of the patients came to surgery. Clearly surgeons seeing patients referred with carotid artery stenosis must be aware of alternative diagnoses and management options, and exercise care when deciding to recommend surgery.

\section{CONClusions}

This review of patients with presumed carotid artery stenosis referred to a cerebrovascular neurosurgeon demonstrates that there has been an increase in the number of patients referred since the August 1991 NASCET publication concluding that endarterectomy is beneficial for symptomatic patients with high grade stenosis. This increase has been most marked from neurologists. There has not been any change in the time from the onset of symptoms to referral, although the benefit of endarterectomy in this group of patients has been seen soon after surgery. The majority of this community-based group of patients had carotid duplex scanning performed by the referring physician. However, the correlation of this investigation with angiography was poor, and angiography remains a necessary investigation for management planning in this population of patients with symptoms of cerebral ischaemia. The majority of patients referred with suspected carotid artery stenosis did not come to surgery. Finally, although the rate of referral of patients has increased since the NASCET findings were published, there was a trend to more of the referrals being for high grade stenosis as reported by pre-referral carotid artery imaging, and less for intermediate grade stenosis. Physicians should remain aware that the question of whether or not surgery is beneficial to this group of patients is not yet resolved, and the continuing referral of these patients to a NASCET centre is most important.

\section{ACKNOWLEDGEMENTS}

This work was supported in part by the James S. McDonnell Neurosurgical Fellowship of the Royal Brisbane Hospital Foundation (TJC). MCW is a Scholar of the Canadian Heart and Stroke Foundation. The authors are grateful to Dr. M. Eliasziw for his helpful suggestions.

The data was presented in part in poster form at the XVIIIth Canadian Congress of Neurological Sciences, Toronto, June, 1993.

\section{REFERENCES}

1. NASCET Investigators. Benefit of carotid endarterectomy for patients with high-grade stenosis of the internal carotid artery. Clinical Alert of the National Institute of Neurological Disorders and Stroke, Bethesda, MD, April 22, 1991.

2. NASCET Collaborators. Beneficial effect of carotid endarterectomy in symptomatic patients with high-grade carotid stenosis. N Engl J Med 1991; 325: 445-453.

3. European Carotid Surgery Trialists' Collaborative Group. MRC European carotid surgery trial: interim results for symptomatic patients with severe $(70-99 \%)$ or with mild (0-29\%) carotid stenosis. Lancet $1991 ; 337 ; 1235-1243$.

4. Kistler JP, Buonanno FS, Gress DR. Carotid endarterectomy - specific therapy based on pathophysiology. $N$ Engl J Med 1991; 325: 505507.

5. Levy LL. Carotid endarterectomy. When and why. JAMA 1991; 266: 3332-3333.

6. Barnett HJM. Carotid endarterectomy evaluation: goals common to all neurologists. Ann Neurol 1992; 32: 832-833.

7. Cusimano MD. An update on the Carotid Endarterectomy Study. Can J Surg 1991; 34: 415 .

8. Reinmuth OM, Dyken ML. Carotid endarterectomy: bright light at the end of the tunnel. Stroke 1992; 22:835-836.

9. Smith RR. Comment on Sieber FE, Toung TJ, Diringer MN, Wang W, Long DM. Preoperative risks predict neurological outcome of carotid endarterectomy related stroke. Neurosurgery 1992; 30: 854.

10. Moore WS, Mohr JP, Najafi H, et al. Carotid endarterectomy: practice guidelines. J Vasc Surg 1992; 15: 469-479.

11. Bamett HJM, Plum F, Walton JN. Carotid endarterectomy: an expression of concern. Stroke 1984; 15: 941-943.

12. Whisnant JP, Fisher L, Robertson JT, Scheinberg P. Does carotid endarterectomy decrease stroke and death in patients with transient ischemic attacks? Ann Neurol 1987; 22: 72-76.

13. Barnett HJM, Barnes RW, Clagett GP, et al. Symptomatic carotid artery stenosis: a solvable problem. Stroke 1992; 23: 1048-1053.

14. McGahan JP. Diagnostic ultrasound in neurological surgery. $I n$ : Youmans JR, ed. Neurological Surgery. Philadelphia: WB Saunders; 1990: 187-204.

15. Lewis BD, James $\mathrm{M}$, Welch TJ. Current applications of duplex and color flow doppler ultrasound imaging: carotid and peripheral vascular system. Mayo Clin Proc 1989; 64: 1147-1157.

16. Dawson DL, Zierler RE, Kohler TR. Role of arteriography in the preoperative evaluation of carotid artery disease. Am J Surg 1991; 161: 619-624. 